Chakmakjian, Z. H., and Bethune, J. E. (1966). New Engl. 7. Med., 275, 862.

Connor, T. B., Hopkins, T. R., Thomas, W. C., jun., Carey, R. A., and Howard, J. E. (1956). F. clin. Endocr., 16, 945.

Dent, C. E. (1962). Brit. med. F., 2, 1495.

Dent, C. E. (1967). Lancet, 2, 613.

Drivsholm, Aa., and Videbæk, Aa. (1966). Acta med. scand., 179, Suppl. No. 445 , p. 187.

Dudley, H. R., Ritchie, A. C., Schilling, A., and Baker, W. H. (1955). New Engl. Ұ. Med., 252, 331 .

Foreman, H., Finnegan, C., and Lushbaugh, C. C. (1956). F. Amer. med.

Ass., 160, 1042. (1968). Calcitonin : Proceedings of the Symposium
Foster, G. V., et al. (1968) on Thyrocalcitonin and the C Cells, edited by S. Taylor, p. 379. London.

Gleckler, W. J. (1956). Ann. intern. Med., 44, 174.

Goldsmith, R. S., and Ingbar, S. H. (1966). New Engl. F. Med., 274, 1. Hebert, L. A., Lemann, J., jun., Petersen, J. R., and Lennon, E. J. (1966). f. clin. Invest., 45, 1886 .

Heckman, B. A., and Walsh, J. H. (1967). New Engl. F. Med., 276, 1082.

Henson, R. A. (1966). 7. roy. Coll. Phycns, 1, 41.

Hirsch, P. F. (1968). Calcitonin: Proceedings of the Symposium on Thyrocalcitonin and the $C$ Cells, edited by $S$. Taylor, p. 11. London.

Holland, J. F., Danielson, E., and Sahagian-Edwards, A. (1953). Proc. Soc. exp. Biol. (N.Y.), 84, 359.
Joplin, G. F. (1965). Thesis submitted to University of London for Ph.D., p. 302.

Kahil, M., Orman, B., Gyorkey, F., and Brown, H. (1967). F. Amer. med. Ass., 201, 721 .

Kennedy, B. J., Tibbetts, D. M., Nathanson, I. T., and Aub, J. C. (1953). Cancer Res., 13, 445 .

Kistler, H. J. (1967). Helv. med. Acta, 33, 447.

Lemann, J., jun., and Mehr, M. P. (1965). Ұ. Amer. med. Ass., 194, 1126

Massry, S. G., Mueller, E., Silverman, A. G., and Kleeman, C. R. (1968). Clin. Res., 16, 128.

Pechet, M. M., Bobadilla, E., Carroll, E. L., and Hesse, R. H. (1967). Amer. F. Med., 43, 696.

Plimpton, C. H., and Gellhorn, A. (1956). Amer. F. Med., 21, 750.

Salvesen, H. A., Hastings, A. B., and McIntosh, J. F. (1924). f. biol. Chem., 60, 311 .

Spencer, H., Vankinscott, V., Lewin, I., and Laszlo, D. (1952). F. clin. Invest., 31, 1023.

Thomas, W. C., jun., Connor, T. B., and Morgan, H. G. (1958). 7. Lab. clin. Med., 52, 11 .

Watson, L. (1964). Quart. 7. Med., 33, 525.

Watson, L. (1966). Aust. Ann. Med., 15, 359.

Wolf, A. V., and Ball, S. M. (1950). Amer. F. Physiol., 160, 353.

Wootton, I. D. P. (1964). Micro-analysis in Medical Biochemistry, 4th ed. London.

\title{
Puerperal Thromboembolism in Relation to the Inhibition of Lactation by Oestrogen Therapy
}

\author{
T. N. A. JEFFCOATE,* M.D., F.R.C.S.ED., F.R.C.o.G. ; JANINE MILLER,* M.B., CH.B., M.R.C.o.G. \\ R. F. ROOS,* M.B., CH.B., M.R.C.o.G. ; V. R. TINDALL, † M.D., F.R.C.S.ED., M.R.C.O.G.
}

Brit. med. F., 1968, 4, 19-25

\begin{abstract}
Summary : An analysis was made of 111 consecutive $\checkmark$ cases of puerperal thromboembolism by the age, parity, mode of delivery, and lactation habit of the women concerned, and the findings were compared with those from control groups.
\end{abstract}

The statistics show that inhibition of lactation by means of ethinyloestradiol is associated with a threefold increase in thromboembolism, although the effect is seen mainly in women who have an operative delivery and who are aged more than 25 years. Among women aged more than 35 years who have an assisted delivery, inhibition of lactation is accompanied by a tenfold increase in the incidence of puerperal thromboembolism.

Advancing age and operative intervention (especially caesarean section) are in themselves predisposing causes of deep venous thrombosis and embolism. They can also constitute indications for inhibiting lactation. This makes it difficult to assess whether the relation of thromboembolism to inhibition of lactation or to the administration of oestrogen is real or apparent. Doubts on the interpretation of the findings are raised by the fact that the number of fatal cases of puerperal thromboembolism in England and Wales, and of non-fatal cases in the hospitals under review, has not increased in recent years despite a progressive decrease in breast-feeding. Nevertheless, the evidence suggests that although the administration of ethinyloestradiol is not by itself enough to cause puerperal thromboembolism, it may be a factor which can tip the scales in women who are already predisposed to suffer this condition.

Any thromboembolic hazard associated with administration of oestrogens for inhibiting lactation is probably acceptable except in women known to be at special risk by reason of age, operative delivery, obesity, and a past history of thromboembolic episodes.

\section{Introduction}

It was first suggested by Daniel, Campbell, and Turnbull (1967) that suppression (or inhibition) of lactation favours the development of deep venous thrombosis and embolism in puerperal women. From information derived from the Cardiff Birth Survey these workers concluded that the inhibition of lactation in mothers aged 25 and more is associated with a tenfold increase in the incidence of thromboembolism, and postulated that the administration of oestrogen may play a part in this. Following this, Daniel, Bloom, Giddings, Campbell, and Turnbull (1968) showed that the administration of relatively large amounts of diethylstilboestrol increases the coagulability of blood by raising the level of factor IX. In the original Cardiff series the oestrogen used was diethylstilboestrol administered in divided doses up to a total of 210-330 mg. during the course of nine days. This dosage, it may be noted, is higher than is usually given, and work carried out many years ago indicated that a total of $45-50 \mathrm{mg}$. of diethylstilboestrol during four to seven days is generally adequate to inhibit lactation (Jeffcoate, Lister, Hargreaves, and Roberts, 1948).

There are some who question the efficacy of oestrogen therapy to inhibit lactation, irrespective of dosage, and the literature pertaining to this was reviewed by Hodge (1967). Differences in experience and opinion may in large measure reflect the timing of the administration of the hormone. The evidence suggests that the sooner after delivery oestrogen is given the more likely is it to inhibit breast activity. Oestrogens will not suppress lactation which is already established. Whatever be their efficacy, there is no question that oestrogens are widely used with the object of inhibiting or suppressing lactation, and it is therefore of considerable importance to determine whether all or certain of the preparations available predispose to puer-

\footnotetext{
* Department of Obstetrics and Gynaecology, University of Liverpool, Liverpool 3.

t Department of Obstetrics and Gynaecology, the Welsh National School of Medicine, Cardiff.
} 
peral thromboembolism, and whether suppression of lactation by itself (without any hormone being administered) has any effect.

So many possible agents are concerned in the aetiology of puerperal venous thrombosis and embolism that it is difficult to assess the significance of each. The presence or absence of breast-feeding cannot readily be separated from factors, such as age, parity, difficult delivery, and general health, which may have governed a decision to inhibit lactation.

This difficulty is emphasized by an analysis of the hospital inpatient inquiry returns for $1962-4$, which was published by Hill and Wilson (1968). After correcting for age, parity, and mode of delivery, they concluded that puerperal thromboembolism occurs twice as often after a stillbirth as after a live birth. Information about the administration of oestrogen in their cases was not available, but lactation must inevitably have been inhibited by one means or another after the birth of a dead baby. This still leaves open the question of whether the circumstances of the stillbirth may in themselves have played some part in predisposing to thromboembolism.

In a previous report (Jeffcoate and Tindall, 1965) based on a study of the experience at the Liverpool Maternity Hospital during the years 1953-63, it was shown that of the associated factors examined those most significantly related to the occurrence of puerperal thromboembolism were (1) the age and parity of the patient and (2) the mode of delivery. The incidence was found to be three times higher after caesarean section than after any form of vaginal delivery. At the time of the original inquiry, however, the lactation habit of affected women was not studied. When the possible importance of breast-feeding was raised by the Cardiff workers it was decided to re-examine our original material for the years 1956-63, and to add to it (1) the experience of the same hospital during the years 1964-6 and (2) the experience of Mill Road Maternity Hospital, Liverpool, during the years 1958-66 inclusive. Cases of puerperal superficial phlebothrombosis, a condition which presents a different clinical picture and has other aetiological factors, were not included.

\section{Method and Criteria}

The statistics presented here are based on the examination of case records, a method which has the disadvantages attached to any retrospective survey. In this instance it means that only recorded cases of deep venous thrombosis and embolism are included. The condition therefore had to be clinically evident, and the diagnosis, which is always subject to individual clinical opinion, beyond reasonable doubt. Similar diagnostic criteria were in use at both hospitals at the times in question. The figures are made more incomplete by the fact that they do not incude those cases in which women, having developed deep venous thrombosis after discharge from hospital, were either treated at home or were referred to another hospital for treatment. Though we have reason to believe there were not many of these, it has to be accepted that the true incidence of clinically evident puerperal thromboembolism is somewhat higher than is here stated. The lack of follow-up studies, however, applies equally to breast-feeding and non-breastfeeding women.

To provide control series a study was made of the records of one out of every 100 consecutive women delivered in the same hospitals during the same period.

A decision on whether or not a woman was lactating was made according to the situation on the seventh day after delivery, a criterion similar to the one adopted in the Cardiff survey. In assessing parity, pregnancies terminating before the twenty-eighth week were not counted. Women subjected to caesarean section or forceps or breech delivery were classified as having an assisted delivery. These standards were applied to both the affected and the control series.
Oestrogen Therapy.-At both hospitals it was the routine practice, when it was decided to inhibit lactation, to administer ethinyloestradiol by mouth, beginning as soon as possible after the woman's delivery was complete. This was given two or three times daily in gradually diminishing amounts for seven days. The dose on the first day was $0.35 \mathrm{mg}$., and this was reduced by $0.05 \mathrm{mg}$. daily. So the total dose administered to each woman was $1.4 \mathrm{mg}$., which is reckoned to be equivalent in activity to $50-70 \mathrm{mg}$. of stilboestrol (Jeffcoate et al., 1948).

\section{Presentation of Results}

The control cases were analysed by age, parity, mode of delivery, and lactation habit ${ }^{1}$ to give a picture of the hospital community at the time and to show how many women fell into each of the groups. By breaking down the cases of thromboembolism into similar groups it was then possible to calculate the incidence of thromboembolism per 1,000 women in each category. The figures shown in Table I, which represent a breakdown by age alone, illustrate the method employed. If for any group there were no control patients an incidence could not be calculated, and no figure appears in the Tables. If any group contained fewer than five (equivalent to 500) control cases, the calculated incidence is regarded as unreliable, and the figure in the Table is marked with an asterisk.

TABLE I.-Liverpool Maternity Hospital (1956-66 inclusive)

\begin{tabular}{|c|c|c|c|c|}
\hline Age in Years: & $<25$ & $25-34$ & $35+$ & Total \\
\hline $\begin{array}{l}\text { Sample of control deliver- } \\
\text { ies ( } 1 \text { in } 100 \text { cases) }\end{array}$ & $\begin{array}{r}119 \\
(35 \cdot 7 \%)\end{array}$ & $\begin{array}{r}179 \\
(53.8 \%)\end{array}$ & $\begin{array}{r}35 \\
(10.5 \%)\end{array}$ & 333 \\
\hline $\begin{array}{l}\text { Calculated total control } \\
\text { deliveries } \\
\text { Cases of thromboembol- }\end{array}$ & 11,900 & 17,900 & 3,500 & $33,300^{*}$ \\
\hline Incidence of puerperal & 14 & 29 & 29 & 72 \\
\hline 1,000 deliveries & $1 \cdot 2$ & $1 \cdot 6$ & $8 \cdot 3$ & $2 \cdot 2$ \\
\hline
\end{tabular}

* The actual number of recorded deliveries in the hospital was 33,627.

\section{Findings at Liverpool Maternity Hospital}

The number of women delivered in this hospital during the 11-year period 1956-66 was 33,627, and 91 of these suffered deep venous thrombosis or embolism, or both. The incidence of recorded thromboembolism was therefore 2.70 per 1,000 births. The vascular accident occurred during pregnancy in 19 cases and during the puerperium in 72 . The incidence of puerperal thromboembolism was therefore 2.14 per 1,000 births. Of the 72 women with puerperal thromboembolism 26 were lactating on the seventh day.

The number of control patients studied was 333, a figure which is three fewer than one-hundredth of the total recorded deliveries. This slight discrepancy is explained by the fact that, at this particular hospital, control case sheets were abstracted for each year separately. Of the control women 212 (almost $64 \%$ ) attempted breast-feeding, and 121 had lactation inhibited. From this it can be calculated that 46 of the 62 women who developed thromboembolism should have been lactating, whereas, as mentioned previously, the actual number was 26. This overall picture is confirmed by the calculated incidence of thromboembolism, which is 1.2 per 1,000 among lactating women and 3.8 per 1,000 among those who had lactation inhibited. For parity groups 1, 2, and 3 the comparable rates are 1.0 and 3.4 per 1,000 .

It is next necessary to examine the influence of other factors, and the breakdown of our cases by age, parity, and mode of delivery is shown in Tables II and III. Consideration of these suggests the following conclusions.

${ }^{1}$ The weight of the woman is another factor of some importance in the aetiology of thromboembolism, but the records were not sufficiently complete to permit a study of this. 
TABLe II.-Liverpool Maternity Hospital (1956-66 Inclusive). Number of Cases of Puerperal Thromboembolism Among Lactating Women Against the Number of Control Cases in Each Category (e.g., 5/40). The Calculated Incidence per 1,000 Deliveries is Shown in Parentheses.

\begin{tabular}{|c|c|c|c|c|c|c|c|c|c|}
\hline \multirow{3}{*}{ Age in Years } & \multicolumn{6}{|c|}{ Parity } & \multirow{2}{*}{\multicolumn{3}{|c|}{ Total }} \\
\hline & \multicolumn{2}{|c|}{1} & \multicolumn{2}{|c|}{2 and 3} & \multicolumn{2}{|c|}{4 and More } & & & \\
\hline & N.D. & Ass.D. & N.D. & Ass.D. & N.D. & Ass.D. & N.D. & Ass.D. & All Deliveries \\
\hline $\begin{array}{l}<25 \\
25-34 \\
35+\end{array}$ & $\begin{array}{l}5 / 40(1 \cdot 3) \\
2 / 17(1 \cdot 2) \\
0 / 1(0.0)^{*}\end{array}$ & $\begin{array}{l}2 / 19(1 \cdot 1) \\
2 / 23(0.9) \\
0 / 4(0 \cdot 0)^{*}\end{array}$ & $\begin{array}{l}0 / 14(0 \cdot 0) \\
3 / 50(0 \cdot 6) \\
1 / 5(2 \cdot 0)\end{array}$ & $\begin{array}{l}0 / 4\left(0.0^{*}\right) \\
2 / 9(2.2) \\
1 / 3\left(3.3^{*}\right)\end{array}$ & $\begin{array}{l}0 / 0(-\overrightarrow{0}) \\
2 / 16(1 \cdot 3) \\
4 / 3\left(1 \cdot 3^{*}\right)\end{array}$ & $\begin{array}{l}0 / 1\left(0.0^{*}\right) \\
0 / 2\left(0.0^{*}\right) \\
2 / 1\left(20.0^{*}\right)\end{array}$ & $\begin{array}{l}5 / 54(0.9) \\
7 / 83(0.8) \\
5 / 9(5.6)\end{array}$ & $\begin{array}{l}2 / 24(0.8) \\
4 / 34(1.2) \\
3 / 8(3.8)\end{array}$ & $\begin{array}{c}7 / 78(0.9) \\
11 / 117(0.9) \\
8 / 17(4 \cdot 7)\}_{(1 / 6)}^{19 / 134}\end{array}$ \\
\hline Total .. & $7 / 58(1 \cdot 2)$ & $4 / 46(0.9)$ & $4 / 69(0.6)$ & $3 / 16(1.9)$ & $6 / 19(3.2)$ & $2 / 4\left(5 \cdot 0^{*}\right)$ & $17 / 146(1 \cdot 2)$ & $9 / 66(1.4)$ & $26 / 212(1 \cdot 2)$ \\
\hline $\begin{array}{l}\text { Deliveries: } \\
\text { All } \\
\text { N.D. } \\
\text { Ass.D. }\end{array}$ & \multicolumn{2}{|c|}{$11 / 104(1 \cdot 1)$} & \multicolumn{2}{|c|}{$7 / 85(0.8)$} & \multicolumn{2}{|c|}{$8 / 23(3.5)$} & \multicolumn{2}{|c|}{$26 / 212(1 \cdot 2)$} & \\
\hline
\end{tabular}

In this and the following tables: N.D. - Normal delivery. Ass.D. = Assisted delivery. * Figure calculated on fewer than 5 (equivalent to 500 ) control cases.

Table III.-Liverpool Maternity Hospital (1956-66 Inclusive). Number of Cases of Puerperal Thromboembolism Among Women Who Had Lactation Inhibited Against the Number of Control Cases in Each Category (e.g., 1/12). The Calculated Incidence per 1,000 Deliveries is Shown in Parentheses.

\begin{tabular}{|c|c|c|c|c|c|c|c|c|c|}
\hline \multirow{3}{*}{ Age in Years } & \multicolumn{6}{|c|}{ Parity } & \multirow{2}{*}{\multicolumn{3}{|c|}{ Total }} \\
\hline & \multicolumn{2}{|c|}{1} & \multicolumn{2}{|c|}{2 and 3} & \multicolumn{2}{|c|}{4 and More } & & & \\
\hline & N.D. & Ass.D. & N.D. & Ass.D. & N.D. & Ass.D. & N.D. & Ass.D. & All Deliveries \\
\hline $\begin{array}{l}<25 \\
25-34 \\
35+\end{array}$ & $\begin{array}{l}1 / 12(0.8) \\
4 / 9(4.4) \\
0 / 2\left(0.0^{*}\right)\end{array}$ & $\begin{array}{l}4 / 10(4 \cdot 0) \\
3 / 6(5 \cdot 0) \\
7 / 1\left(70 \cdot 0^{*}\right)\end{array}$ & $\begin{array}{l}1 / 13(0 \cdot 8) \\
6 / 36(1 \cdot 7) \\
2 / 5(4 \cdot 0)\end{array}$ & $\begin{array}{l}1 / 6(1 \cdot 7) \\
3 / 6(5 \cdot 0) \\
5 / 2\left(25 \cdot 0^{*}\right)\end{array}$ & $\begin{array}{l}0 / 0(-7) \\
1 / 5(2.0) \\
4 / 7(5.7)\end{array}$ & $\begin{array}{l}0 / 0((-) \\
1 / 0(-) \\
3 / 1\left(30 \cdot 0^{*}\right)\end{array}$ & $\begin{array}{r}2 / 25(0.8) \\
11 / 50(2 \cdot 2) \\
6 / 14(4 \cdot 3)\end{array}$ & $\begin{array}{c}5 / 16(3 \cdot 1) \\
7 / 12(5 \cdot 8) \\
15 / 4\left(38 \cdot 4^{*}\right)\end{array}$ & $\left.\begin{array}{c}7 / 41(1 \cdot 7) \\
18 / 62(2.9) \\
21 / 18(11 \cdot 7)\end{array}\right\} \begin{array}{c}39 / 80 \\
(4 \cdot 9)\end{array}$ \\
\hline Total ... & $5 / 23(2 \cdot 2)$ & $14 / 17(8 \cdot 2)$ & $9 / 54(1 \cdot 7)$ & $9 / 14(6 \cdot 4)$ & $5 / 12(4 \cdot 2)$ & $4 / 1\left(40 \cdot 0^{*}\right)$ & $19 / 89(2 \cdot 1)$ & $27 / 32(8 \cdot 4)$ & $46 / 121(3.8)$ \\
\hline $\begin{array}{l}\text { Deliveries: } \\
\text { All } \\
\text { N.D. } \\
\text { Ass.D. }\end{array}$ & \multicolumn{2}{|c|}{$19 / 40(4 \cdot 8)$} & \multicolumn{2}{|c|}{$18 / 68(2 \cdot 6)$} & \multicolumn{2}{|c|}{$9 / 13(6 \cdot 9)$} & \multicolumn{2}{|c|}{$46 / 121(3 \cdot 8)$} & \\
\hline
\end{tabular}

\section{Age}

Among lactating women (Table II) age has little effect until the borderline of 35 years is reached. After this the incidence of thromboembolism mounts steeply in all parity groups, being increased five times overall. A similar trend is shown among women who did not lactate (Table III). In Table III there are subgroupings by mode of delivery, but, disregarding this factor, the incidence among non-lactating women is 1.7 per 1,000 for those less than 25 years and 4.9 per 1,000 for those older. Again, however, 35 years is a more significant divisional point. The incidence for women aged 25 to 34 is 2.9 per 1,000 , whereas for women aged 35 and more the figure rises to 11.7 per 1,000 (almost seven times greater than that for women less than 25 years of age). A similar picture is presented by studying the effect of age irrespective of parity, mode of delivery, and lactation. Thus, in Table $I$ it will be seen that considering all cases of thromboembolism, the incidences for the three age groups are $1.2,1.6$, and 8.3 per 1,000 respectively.

\section{Parity}

The figures in Tables II and IV, and to a less extent those in Table III, suggest that, irrespective of lactation habit and mode of delivery, the incidence of thromboembolism increases with high parity. However, as was suggested previously (Jeffcoate and Tindall, 1965), the having of many babies generally means older age, and the latter factor is likely to be the more important.

TABLE IV.-Liverpool Maternity Hospital (1956-66 inclusive)

\begin{tabular}{|c|c|c|c|c|}
\hline Parity: & 1 & 2 and 3 & 4 and More & Total \\
\hline \multirow{5}{*}{ 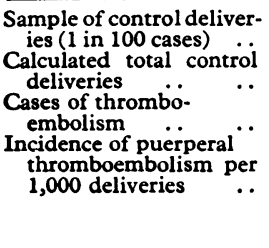 } & $\begin{array}{c}144 \\
(43 \cdot 2 \%)\end{array}$ & $\begin{array}{c}153 \\
(46.0 \%)\end{array}$ & $\begin{array}{c}36 \\
(10 \cdot 8 \%)\end{array}$ & 333 \\
\hline & 14,400 & 15,300 & 3,600 & 33,300 \\
\hline & 30 & 25 & 17 & 72 \\
\hline & $2 \cdot 1$ & 1.6 & \multirow[t]{2}{*}{$4 \cdot 7$} & \multirow[t]{2}{*}{$2 \cdot 2$} \\
\hline & \multicolumn{2}{|c|}{1.9} & & \\
\hline
\end{tabular}

Leaving aside "grand" multiparity, the breakdown of our cases suggests that 1-paras are rather more likely than 2- or 3-paras to develop puerperal thromboembolism (Table IV). This may reflect a higher incidence of operative deliveries in that group (see below).

\section{Mode of Delivery}

The analysis of our series, unlike that published by Daniel et al. (1967), indicates that mode of delivery is very significantly associated with puerperal deep venous thrombosis and embolism. Among lactating women the incidences for spontaneous and assisted delivery are similar, but among women who had lactation inhibited the chance of thromboembolism is increased four times by operative delivery. Moreover, comparing Tables II and III, it will be seen that for women less than 25 years of age inhibition of lactation has no effect unless the delivery is assisted, when the risk rises three times. This is different from the experience of the Cardiff workers, who concluded that inhibition of lactation in women less than 25 year:; of age had no effect, irrespective of mode of delivery.

Disregarding age, when women delivered normally do not bre:lit-feed the incidence of thromboembolism is only doubled; among those who have assisted delivery inhibition of lactation is associated with a six times increased risk. For the oldest age group of women failure to lactate considerably increases the risk if they have a complicated delivery, whereas it has virtually no effect if their delivery is normal. The importance of operative intervention may be even greater than is indicated by the statistics presented here because a few of the women who suffered puerperal thromboembolism and who are classified as having a spontaneous delivery had other operations such as manual removal of the placenta under general anaesthesia or tubal ligation in the puerperium. To avoid complicating the presentation these were not put in separate categories.

Another disadvantage of accepting the classification " assisted delivery" without qualification, which was done to conform with the original Cardiff study, is that it gives no idea of the severity of the operative intervention. Thus an 
easy low-forceps extraction under local anaesthesia involves little more trauma than spontaneous delivery, whereas caesarean section is a procedure of an entirely different order. A young woman of low parity is likely to have a minor procedure, whereas an elderly primigravida is prone to have a more difficult vaginal operation or even caesarean section.

Table $\mathrm{V}$ shows that primiparae who developed puerperal thromboembolism are more likely to have had an assisted delivery than are multiparae. Assisted delivery among older women developing thromboembolism was unusually frequent, and often involved more extensive surgical intervention. Of the 58 women aged 25 years or more 41 were paras $1-3$, and 23 of these $(56 \%)$ had operative deliveries. The incidence of operative delivery among the corresponding control group was only $30 \%$. Twenty-nine women who suffered thromboembolism were aged 35 years or more, and 18 of these had an assisted delivery.

TABLE V.-Liverpool Maternity Hospital (1956-66 inclusive). Actual Number of Cases of Puerperal Thromboembolism by Age, Parity, and Mode of Delivery

\begin{tabular}{|c|c|c|c|c|c|c|c|c|c|}
\hline \multirow{3}{*}{\multicolumn{2}{|c|}{ Age in Years }} & \multicolumn{6}{|c|}{ Parity } & \multirow{2}{*}{\multicolumn{2}{|c|}{ Total }} \\
\hline & & \multicolumn{2}{|r|}{1} & \multicolumn{2}{|c|}{2 and 3} & \multicolumn{2}{|c|}{4 and More } & & \\
\hline & & N.D. & Ass.D. & N.D. & Ass.D. & N.D. & Ass.D. & N.D. & Ass.D. \\
\hline $\begin{array}{r}25 \\
25-34 \\
35+\end{array}$ & $\because$. & $\begin{array}{l}6 \\
6 \\
0\end{array}$ & $\begin{array}{l}6 \\
5 \\
7\end{array}$ & $\begin{array}{l}1 \\
9 \\
3\end{array}$ & $\begin{array}{l}1 \\
5 \\
6\end{array}$ & $\begin{array}{l}0 \\
3 \\
8\end{array}$ & $\begin{array}{l}0 \\
1 \\
5\end{array}$ & $\begin{array}{r}7 \\
18 \\
11\end{array}$ & $\begin{array}{r}7 \\
11 \\
18\end{array}$ \\
\hline Total & $\ldots$ & 12 & 18 & 13 & 12 & 11 & 6 & 36 & 36 \\
\hline
\end{tabular}

The interim conclusion drawn from a study of the experience of the Liverpool Maternity Hospital is that, although women who have lactation inhibited show a greater incidence of thromboembolism, any effect is considerably modified by the more important factors of age and method of delivery. In illustration of this it may be noted that among the 72 cases of thromboembolism there were eight cases of pulmonary embolism. The ages of the patients concerned were: less than 25 years in one, 25 to 34 in one, and 35 or more in six. Two of the women died from embolism. Both had had lactation inhibited with ethinyloestradiol, but they had been delivered by caesarean section and were aged 39 and 41 years respectively. Moreover, the older one suffered from diabetes mellitus.

\section{Findings at Mill Road Maternity Hospital}

During the nine years 1958-66 there were 30,833 deliveries in this hospital, and 65 cases of thromboembolism were recorded. Three of the women concerned were admitted to hospital on account of deep venous thrombosis, having been previously delivered at home. Excluding these, the incidence of thromboembolism was 2.1 per 1,000 hospital births. In 26 of the cases ( $42 \%$ ) thromboembolism occurred during pregnancy, leaving only 39 puerperal cases for analysis. In 21 $(54 \%)$ of these lactation had been inhibited by means of ethinyloestradiol; this is approximately double the expected number calculated on a known breast feeding rate of $73 \%$ for the hospital community on the seventh day.

The total number of records of control patients studied, abstracted as indicated previously, was 308 . Based on these, the incidence of thromboembolism by age, parity, mode of delivery, and lactation habit was calculated to give the findings shown in Tables VI and VII. The figures from this hospital are too small to draw many firm conclusions, but they go to confirm the experience at the Liverpool Maternity Hospital. Overall, the incidence of thromboembolism was increased three to four times when lactation was inhibited. The effect of not lactating was manifested mainly in women aged more than 25 years and in those who had an assisted delivery (especially if they were of low parity). Among lactating women, however, the mode of delivery did not influence the incidence of thromboembolism except possibly in those aged 35 and more. A rising incidence of puerperal thromboembolism with age is apparent only in non-lactating women.

\section{Total Liverpool Experience}

Combining the findings in the two hospitals offers a study of 111 cases of puerperal thromboembolism and of 641 control cases. The overall incidence of evident puerperal thrombo-

TABle VI.-Mill Road Maternity Hospital (1958-66 Inclusive). Number of Cases of Puerperal Thromboembolism Among Lactating Women Against the Number of Control Cases in Each Category (e.g., 5/54). The Calculated Incidence per 1,000 Deliveries is Shown in Parentheses.

\begin{tabular}{|c|c|c|c|c|c|c|c|c|c|}
\hline \multirow{3}{*}{$f$ ge in Years } & \multicolumn{6}{|c|}{ Parity } & & \multirow{2}{*}{\multicolumn{2}{|c|}{ Total }} \\
\hline & \multicolumn{2}{|c|}{1} & \multicolumn{2}{|c|}{2 and 3} & \multicolumn{2}{|c|}{4 and More } & & & \\
\hline & N.D. & Ass.D. & N.D. & Ass.D. & N.D. & Ass.D. & N.D. & Ass.D. & All Deliveries \\
\hline $\begin{array}{l}<25 \\
25-34 \\
35+\end{array}$ & $\begin{array}{l}5 / 54(0.9) \\
0 / 12(0 \cdot 0) \\
0 / 2\left(0.0^{*}\right)\end{array}$ & $\begin{array}{l}1 / 9(1 \cdot 1) \\
1 / 8(1 \cdot 3) \\
0 / 1\left(0 \cdot 0^{*}\right)\end{array}$ & $\begin{array}{l}3 / 39(0.9) \\
4 / 39(1.0) \\
1 / 6(1 \cdot 7)\end{array}$ & $\begin{array}{l}0 / 1\left(0 \cdot 0^{*}\right) \\
0 / 3\left(0 \cdot 0^{*}\right) \\
0 / 1\left(0 \cdot 0^{*}\right)\end{array}$ & $\begin{array}{l}0 / 7(0.0) \\
2 / 35(0 \cdot 6) \\
0 / 15(0.0)\end{array}$ & $\begin{array}{l}0 / 0(-\overrightarrow{)}) \\
0 / 0(\overrightarrow{-}) \\
1 / 1\left(10 \cdot 0^{*}\right)\end{array}$ & $\begin{array}{l}8 / 100(0.8) \\
6 / 86(0.7) \\
1 / 23(0.4)\end{array}$ & $\begin{array}{l}1 / 10(1 \cdot 0) \\
1 / 11(0 \cdot 9) \\
1 / 3\left(3 \cdot 3^{*}\right)\end{array}$ & 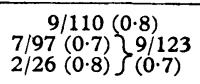 \\
\hline Total .. & $5 / 68(0 \cdot 7)$ & $2 / 18(1 \cdot 1)$ & $8 / 84(1 \cdot 0)$ & $0 / 5(0.0)$ & $2 / 57(0.4)$ & $1 / 1\left(10 \cdot 0^{*}\right)$ & $15 / 209(0 \cdot 7)$ & $3 / 24(1 \cdot 3)$ & $18 / 233(0.8)$ \\
\hline $\begin{array}{l}\text { Deliveries: } \\
\text { All } \\
\text { N.D. } \\
\text { Ass.D. }\end{array}$ & & $\begin{array}{r}15 / 1 \\
13 / 1 \\
2 / 2\end{array}$ & \multicolumn{2}{|c|}{$8 / 89(0.9)$} & \multicolumn{2}{|c|}{$3 / 58(0.5)$} & \multicolumn{2}{|c|}{$18 / 233(0.8)$} & \\
\hline
\end{tabular}

TABle VII.-Mill Road Maternity Hospital (1958-66 Inclusive). Number of Cases of Puerperal Thromboembolism Among Women Who Had Lactation Inhibited Against the Number of Control Cases in Each Category (e.g., 0/16). The Calculated Incidence per 1,000 Deliveries is Shown in Parentheses.

\begin{tabular}{|c|c|c|c|c|c|c|c|c|c|}
\hline \multirow{3}{*}{ Age in Years } & \multicolumn{6}{|c|}{ Parity } & \multirow{2}{*}{\multicolumn{3}{|c|}{ Tota! }} \\
\hline & \multicolumn{2}{|c|}{1} & \multicolumn{2}{|c|}{2 and 3} & \multicolumn{2}{|c|}{4 and More } & & & \\
\hline & N.D. & Ass.D. & N.D. & Ass.D. & N.D. & Ass.D. & N.D. & Ass.D. & All Deliveries \\
\hline $\begin{array}{l}<25 \\
25-34 \\
35+\end{array}$ & $\begin{array}{l}0 / 16(0.0) \\
1 / 7(1.4) \\
0 / 0(-)\end{array}$ & $\begin{array}{l}1 / 6(1 \cdot 7) \\
2 / 0(二) \\
1 / 0(-)\end{array}$ & $\begin{array}{r}1 / 9(1 \cdot 1) \\
4 / 10(4 \cdot 0) \\
0 / 3\left(0 \cdot 0^{*}\right)\end{array}$ & $\begin{array}{l}0 / 3\left(0 \cdot 0^{*}\right) \\
3 / 1\left(30 \cdot 0^{*}\right) \\
0 / 0(-)\end{array}$ & $\begin{array}{l}1 / 1\left(10 \cdot 0^{*}\right) \\
4 / 12(3 \cdot 3) \\
2 / 3\left(6 \cdot 7^{*}\right)\end{array}$ & $\begin{array}{c}0 / 0(-) \\
0 \cdot 3(0 \cdot 0 *) \\
1 / 1\left(10 \cdot 0^{*}\right)\end{array}$ & $\begin{array}{l}2 / 26(0 \cdot 8) \\
9 / 29(3 \cdot 1) \\
2 / 6(3 \cdot 3)\end{array}$ & $\begin{array}{c}1 / 9(1 \cdot 1) \\
5 / 4\left(12 \cdot 5^{*}\right) \\
2 / 1\left(20 \cdot 0^{*}\right) \\
\end{array}$ & 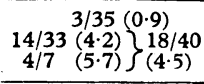 \\
\hline Total .. & $1 / 23(0.4)$ & $4 / 6(6 \cdot 7)$ & $5 / 22(2 \cdot 3)$ & $3 / 4\left(7 \cdot 5^{*}\right)$ & $7 / 16(4 \cdot 4)$ & $1 / 4\left(2 \cdot 5^{*}\right)$ & $13 / 61(2 \cdot 1)$ & $8 / 14(5 \cdot 7)$ & $21 / 75(2 \cdot 8)$ \\
\hline $\begin{array}{l}\text { Deliveries: } \\
\text { Al1 } \\
\text { N.D. } \\
\text { Ass.D. }\end{array}$ & & $\begin{array}{l}13 / 5 \\
6 / 45 \\
7 / 10\end{array}$ & \multicolumn{2}{|c|}{$8 / 26(3 \cdot 1)$} & \multicolumn{2}{|c|}{$8 / 20(5 \cdot 0)$} & \multicolumn{2}{|c|}{$21 / 75(2 \cdot 8)$} & \\
\hline
\end{tabular}


TABle VIII.-Total Liverpool Series. Incidence of Puerperal Thromboembolism Among Lactating Women Against the Number of Control Cases in Each Category (e.g., 10/94). The Calculated Incidence per 1,000 Deliveries is Shown in Parentheses.

\begin{tabular}{|c|c|c|c|c|c|c|c|c|c|}
\hline \multirow{3}{*}{ Age in Years } & \multicolumn{6}{|c|}{ Parity } & \multirow{2}{*}{\multicolumn{3}{|c|}{ Total }} \\
\hline & \multicolumn{2}{|c|}{1} & \multicolumn{2}{|c|}{2 and 3} & \multicolumn{2}{|c|}{4 and More } & & & \\
\hline & N.D. & Ass.D. & N.D. & Ass.D. & N.D. & Ass.D. & N.D. & Ass.D. & All Deliveries \\
\hline $\begin{array}{l}<25 \\
25-34 \\
35+ \\
\end{array}$ & $\begin{array}{r}10 / 94(1 \cdot 1) \\
2 / 29(0 \cdot 7) \\
0 / 3\left(0: 0^{*}\right) \\
\end{array}$ & $\begin{array}{r}3 / 28(1 \cdot 1) \\
3 / 31(1 \cdot 0) \\
0 / 5(0.0) \\
\end{array}$ & $\begin{array}{l}3 / 53(0.6) \\
7 / 89(0.8) \\
2 / 11(1.8) \\
\end{array}$ & $\begin{array}{r}0 / 5(0.0) \\
2 / 12(1 \cdot 7) \\
1 / 4\left(2 \cdot 5^{*}\right) \\
\end{array}$ & $\begin{array}{r}0 / 7(0.0) \\
4 / 51(0 \cdot 8) \\
4 / 18(2 \cdot 2)\end{array}$ & $\begin{array}{l}0 / 1\left(0.0^{*}\right) \\
0 / 2\left(0.0^{*}\right) \\
3 / 2\left(15 \cdot 0^{*}\right)\end{array}$ & $\begin{array}{c}13 / 154(0 \cdot 8) \\
13 / 169(0 \cdot 8) \\
6 / 32(1 \cdot 9) \\
\end{array}$ & $\begin{array}{l}3 / 34(0.9) \\
5 / 45(1.1) \\
4 / 11(3.6)\end{array}$ & $\left.\begin{array}{r}16 / 188(0 \cdot 8) \\
18 / 214(0 \cdot 8) \\
10 / 43(2 \cdot 3)\end{array}\right\} \begin{array}{l}(1 \cdot 1) \\
\end{array}$ \\
\hline Total ... & $12 / 126(1 \cdot 0)$ & $6 / 64(0.9)$ & $12 / 153(0.8)$ & $3 / 21(1 \cdot 4)$ & $8 / 76(1 \cdot 1)$ & $3 / 5(6.0)$ & $32 / 355(0.9)$ & $12 / 90(1 \cdot 3)$ & $44 / 445(1 \cdot 0)$ \\
\hline $\begin{array}{l}\text { Deliveries: } \\
\text { All } \\
\text { N.D. } \\
\text { Ass.D. }\end{array}$ & \multicolumn{2}{|c|}{$18 / 190(0.9) \quad 33 / 3$} & \multicolumn{2}{|c|}{$15 / 174(0.9)$} & \multicolumn{2}{|c|}{$11 / 81(1 \cdot 4)$} & \multicolumn{2}{|c|}{$44 / 445(1 \cdot 0)$} & \\
\hline
\end{tabular}

TABLE IX.-Total Liverpool Series. Incidence of Puerperal Thromboembolism Among Women Who Had Lactation Inhibited Against the Number of Control Cases in Each Category (e.g., 1/28). The Calculated Incidence per 1,000 Deliveries is Shown in Parentheses.

\begin{tabular}{|c|c|c|c|c|c|c|c|c|c|}
\hline \multirow{3}{*}{ Age in Years } & \multicolumn{6}{|c|}{ Parity } & \multirow{2}{*}{\multicolumn{3}{|c|}{ Total }} \\
\hline & \multicolumn{2}{|c|}{1} & \multicolumn{2}{|c|}{2 and 3} & \multicolumn{2}{|c|}{4 and More } & & & \\
\hline & N.D. & Ass.D. & N.D. & Ass.D. & N.D. & Ass.D. & N.D. & Ass.D. & All Deliveries \\
\hline $\begin{array}{l}<25 \\
25-34 \\
35+ \\
\end{array}$ & $\begin{array}{l}1 / 28(0.4) \\
5 / 16(3 \cdot 1) \\
0 / 2\left(0.0^{*}\right) \\
\end{array}$ & $\begin{array}{l}5 / 16(3 \cdot 1) \\
5 / 6(8 \cdot 3) \\
8 / 1\left(80 \cdot 0^{*}\right) \\
\end{array}$ & $\begin{array}{r}2 / 22(0 \cdot 9) \\
10 / 46(2 \cdot 2) \\
2 / 8(2 \cdot 5) \\
\end{array}$ & $\begin{array}{c}1 / 9(1 \cdot 1) \\
6 / 7(8 \cdot 6) \\
5 / 2\left(25 \cdot 0^{*}\right) \\
\end{array}$ & $\begin{array}{l}1 / 1\left(10 \cdot 0^{*}\right) \\
5 / 17(2 \cdot 9) \\
6 / 10(6 \cdot 0) \\
\end{array}$ & $\begin{array}{l}0 / 0\left(-3^{*}\right) \\
1 / 3\left(3 \cdot 0^{*}\right) \\
4 / 2\left(20^{*}\right) \\
\end{array}$ & $\begin{array}{r}4 / 51(0 \cdot 8) \\
20 / 79(2 \cdot 5) \\
8 / 20(4 \cdot 0) \\
\end{array}$ & $\begin{array}{c}6 / 25(2 \cdot 4) \\
12 / 16(7.5) \\
17 / 5(34 \cdot 0) \\
\end{array}$ & 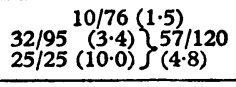 \\
\hline Total .. & $6 / 46(1 \cdot 3)$ & $18 / 23(7 \cdot 8)$ & $14 / 76(1 \cdot 8)$ & $12 / 18(6 \cdot 7)$ & $12 / 28(4 \cdot 3)$ & $5 / 5(10.0)$ & $32 / 150(2 \cdot 1)$ & $35 / 46(7 \cdot 6)$ & $67 / 196(3.4)$ \\
\hline $\begin{array}{l}\text { Deliveries: } \\
\text { All } \\
\text { N.D. } \\
\text { Ass.D. }\end{array}$ & \multicolumn{2}{|c|}{$24 / 69(3 \cdot 5)$} & \multicolumn{2}{|c|}{ 3.1) $\quad 26 / 94(2 \cdot 8)$} & \multicolumn{2}{|c|}{$17 / 33(5 \cdot 2)$} & \multicolumn{2}{|c|}{$67 / 196(3-4)$} & \\
\hline
\end{tabular}

embolism was 1.7 per 1,000 deliveries. The incidence by age, parity, mode of delivery, and lactation habit is shown in Tables VIII, IX, and X. Examination of these strengthens the conclusions drawn from the experience of the individual hospitals. They can be summarized as follows:

(1) The incidence of puerperal thromboembolism is three times higher in those women whose lactation is inhibited by administering ethinyloestradiol than in those who breast-feed their babies ( 3.4 as against 1.0 per 1,000). The difference is seen mostly among those who have an assisted delivery. The incidence is only doubled (2.1 compared with 0.9 per 1,000 ) when the delivery is spontaneous, but is increased six times ( 7.6 compared with 1.3 per 1,000 ) when the delivery is complicated.

TABLE X.-Total Liverpool Sernes. Incidence of Puerperal Thromboembolism in Relation to Age and Parity Regardless of Lactation and Mode of Delivery per 1,000 Deliveries in Each Category

\begin{tabular}{|c|c|c|c|c|c|}
\hline \multirow{2}{*}{\multicolumn{2}{|c|}{ Age in Years }} & \multicolumn{3}{|c|}{ Parity } & \multirow{2}{*}{ Total } \\
\hline & & 1 & 2 and 3 & 4 and More & \\
\hline $\begin{array}{l}<25 \\
25-34 \\
35+\ldots\end{array}$ & $\because$. & $\left.\begin{array}{c}1.1 \\
1.8 \\
7.3\end{array}\right\} 2.5$ & $\left.\begin{array}{c}0 \cdot 7 \\
1 \cdot 6 \\
4 \cdot 0\end{array}\right\}^{2 \cdot 0}$ & $\left.\begin{array}{c}1 \cdot 1 \\
1 \cdot 4 \\
5 \cdot 3\end{array}\right\} 2 \cdot 6$ & $\left.\begin{array}{c}1.0 \\
1.6 \\
5.1\end{array}\right\}^{2 \cdot 3}$ \\
\hline \multirow[t]{2}{*}{ Total } & .. & 1.6 & 1.5 & \multirow[t]{2}{*}{2.5} & \multirow[t]{2}{*}{1.7} \\
\hline & & \multicolumn{2}{|c|}{1.6} & & \\
\hline
\end{tabular}

(2) The incidence of thromboembolism rises with age irrespective of parity, mode of delivery, and lactation habit (Table X). It is especially high in women aged 35 or more. The rates are 1.0, 1.6, and 5.1 per 1,000 deliveries respectively for the three age groups under consideration.

(3) There is a slight suggestion of a rising risk with high parity, the respective incidences being $1.6,1.5$, and 2.5 per 1,000 deliveries for each parity group. This is more apparent in non-lactating women, but any association is probably indirect, being accounted for by concomitant advancing age.

(4) Of all the factors under consideration the most significant, as can be inferred from conclusion 1 (above), is mode of delivery. Thus in women less than 25 years of age, inhibition of lactation has no effect unless they have an assisted delivery, when the incidence is trebled. In young lactating women of low parity, operative intervention does not influence the incidence of thromboembolism, probably because the intervention is minor. In women aged more than 25, however, assisted delivery raises the incidence twofold if they are lactating, and almost sixfold if they are not. Indeed, the woman aged 35 or more, having had an assisted delivery, has a 10 times greater chance of thromboembolism if her lactation function is inhibited than if she breast-feeds her baby. In this respect it has to be recognized that the severity of the operative intervention, together with age and general condition, may determine the decision to inhibit lactation.

(5) The highest incidence of thromboembolism among women of low parity is seen in those who have an assisted delivery and who do not breast-feed. For parity groups 1,2 , and 3 combined the incidence in lactating women is 0.9 per 1,000 deliveries for normal delivery and 1.1 per 1,000 for assisted delivery; in non-lactating women the comparable figures are 1.6 and 7.3 per 1,000 . If advancing age is added to the three factors already under consideration here, then the risk of puerperal thrombosis is probably very high (possibly $40-45$ per 1,000 ), though the figures available to us are too small to be statistically significant.

\section{Discussion}

The statistics on which this communication is based can be handled in several ways, each being attended by difficulties of one type or another. Irrespective of the approach, however, they confirm the overall conclusions of Daniel et al. (1967) to the effect that puerperal thromboembolism is seen more frequently among women in whom lactation is inhibited than among those who breast-feed their babies. But the difference between the two groups of patients is not so great in our series as was reported from Cardiff. For all women the incidence of thromboembolism was three times greater when they did not lactate. For low-parity women aged 25 and older inhibition of lactation was associated with a fourfold increased risk, whereas in Cardiff there was a tenfold increase. If the administration of oestrogens plays a direct part in predisposing the puerperal woman to thromboembolic episodes, it might be argued that the difference between the two centres could be attributed either to our employment of a much smaller dose of hormone for inhibiting lactation or to the use of ethinyloestradiol rather than stilboestrol.

The results of our study also differ from those in Cardiff in that they indicate that age, and especially mode of delivery, 
are of equal if not greater importance than inhibition of lactation in determining the risk of puerperal thromboembolism. Indeed, for women who have spontaneous delivery, inhibition of lactation by administering a moderate dose of ethinyloestradiol does not increase the incidence of thromboembolism if they are less than 25 years of age, and only doubles it if they are older. Our evidence suggests that any dramatic increase in the occurrence of thromboembolic disorders is related to the severity of any operative intervention and also to age. It may well be that major surgery and advancing years of ten underlie both the decision to inhibit lactation and the associated increased risk of thromboembolism. The same may well be true of obesity, but the weights of the patients in these series were not studied.

Apart from the fact that the findings reported here reveal an interplay of several probably more important factors, there are some general considerations which raise serious doubts about any direct effect of inhibition of lactation, or of administering oestrogens for the purpose, in determining puerperal thromboembolism. Though the Reports on Confidential Enquiries into Maternal Deaths in England and Wales (Ministry of Health, 1957, 1960,1963, 1966) show that venous thrombosis and embolism constitute a leading cause of death, the actual number of deaths per annum from this cause did not increase during the period 1952-63 despite a rising number of births. Indeed, the number of fatal puerperal cases showed a fall over the years, the total figure being kept constant by a gradual rise in the number of fatal episodes occurring during pregnancy. The national decrease in the number of fatal puerperal cases occurred despite a general trend away from breast-feeding. ${ }^{2}$

Between 1951 and 1957, and in England and Wales, the proportion of women who attempted breast-feeding fell from $85 \%$ to approximately $78 \%$, varying a little as between domiciliary and hospital deliveries and from one part of the country to another (Ministry of Health, 1957a ; Dykes, 195.7 ; Burns, 1957). Since then the percentage has fallen but the extent is unknown. Reports from the Simpson Memorial Pavilion of Edinburgh Royal Infirmary (1965) indicate that the incidence of breast-feeding among mothers at the time of discharge from that hospital fell from $70 \%$ in 1955 to $26 \%$ in 1965 . At the Royal Maternity Hospital, Glasgow, during the years 1962 and 1963 the percentage of breast-feeders varied from $6.2 \%$ for "grand" multiparae subjected to caesarean section to $42 \%$ for i rimiparae having a normal delivery (Garrey, Paterson, and Evans, 1964). Throughout Scotland as a whole, and in 1965 , only $31 \%$ of mothers ever attempted breast-feeding (Arneil, 1967).

Whether Scottish practice is a measure of the trend in England and Wales as a whole is uncertain. But lactation habits certainly changed among the women delivered in the two hospitals on which this study is based. Up to 1959 and 1960 the incidence of lactation on the seventh day of the puerperium among the control women was $80-90 \%$. After 1960 the incidence fell progressively to approximately $60 \%$. Yet the annual incidence of thromboembolism remained static throughout the whole period. The number of cases did not significantly rise despite the fact that ultimately $40 \%$ of all puerperal women received ethinyloestradiol and did not breast-feed. So far as can be ascertained there was no other change in obstetric management which could have operated to keep the figures static. At both hospitals, from the beginning to the end of the period under review, there was an intensive campaign to recognize and correct pregnancy anaemia; the third stage of labour was managed actively and the incidence of postpartum haemorrhage kept to a low constant figure ; all patients were ambulant and practising physiotherapy from the first day of the puerperium onwards ; and very few women were discharged home before 8 to 10 days after delivery.

${ }^{2}$ Comments in the reports suggest that during the years under review there had been no significant increase in the use of anticoagulants to explain fewer puerperal deaths.
The fact that thromboembolism is now occurring relatively often during pregnancy, whereas formerly it was rare before delivery, is of some interest. In England and Wales during the period 1961-3 there were more deaths from embolism during pregnancy than after caesarean section, an operation known to carry an unusually high risk. In the period 1952-4 only $3 \%$ of the obstetric deaths from thrombosis and embolism in England and Wales occurred before labour; by 1961-3 the figure had risen to $29 \%$.

Our local experience confirms the country-wide trend. At the Liverpool Maternity Hospital antenatal thromboembolism accounted for almost $21 \%$ of all cases during 1956-66. At the Mill Road Maternity Hospital $42 \%$ of the thromboembolic episodes occurred before delivery, a remarkably high figure difficult to explain. The only obvious difference between the practice of the two hospitals is that the Mill Road Maternity Hospital deals mainly with women drawn from the poorer socioeconomic groups, whereas the Liverpool Maternity Hospital caters mainly for the middle classes.

During pregnancy there are high levels of oestrogen and progesterone in circulation. One or other or both of these hormones almost certanly play some part in predisposing women to thromboembolism during pregnancy, as they do women who take oestrogen/progestogen preparations for purposes of contraception (Inman and Vessey, 1968 ; Vessey and Doll, 1968). But pregnant women have always been exposed to this influence, and it is difficult to accept that this is a prime cause of thromboembolism occurring during pregnancy, since it would appear that it did not operate until the last 15 to 20 years.

In this context it is not irrelevant to mention that, during the period 1952-66, 59 pregnant women attending our clinical department were treated empirically with large doses of oestrogen on account of a past history of unexplained recurrent abortion. Of these, 43 were given stilboestrol in amounts which were gradually increased from $45 \mathrm{mg}$. daily in the first trimester to $135 \mathrm{mg}$. daily between the thirty-second and thirtysixth weeks. The other 16 women were given ethinyloestradiol, beginning with $2.25 \mathrm{mg}$. daily and increasing to $6.75 \mathrm{mg}$. daily. Not all these women carried their babies to term, but those who did each received a total of $75,000 \mathrm{mg}$. of stilboestrol or 3,750 $\mathrm{mg}$. of ethinyloestradiol. None of the women concerned, irrespective of the time of delivery, suffered thromboembolism before or after labour.

All these considerations make it necessary to question whether the undoubted association between inhibition of lactation with puerperal thromboembolism is direct or indirect, and, if the former, whether oestrogen therapy is responsible. It has to be reckoned that inhibition of lactation by any means, even the avoidance of suckling and fluid restriction, could be the operative factor. This aspect of the problem was not examined by us because all the non-lactating women in our series received ethinyloestradiol. There is a need for a controlled study in this field.

Meanwhile there is now so much ancillary evidence to indicate that the administration of oestrogens in other circumstances can favour the development of deep venous thrombosis and embolism that it seems justifiable to conclude that probably they play some part in determining any increase in the incidence of puerperal thromboembolism among women who do not breast-feed their babies. But our findings suggest that their role is a secondary one. They appear merely to contribute one more factor to many other factors already operating. Thus ethinyloestradiol administered in reasonable doses for the purpose of inhibiting lactation has no effect in young women having a normal delivery. If, however, the factor of advancing age is already present then its administration appears to raise the incidence from approximately 1 to 2 per 1,000 deliveries. Again, women having an operative delivery already carry a relatively high risk of thromboembolism; ethinyloestradiol given to them may have a summation effect 
to increase the risk six times. Fundamental determining factors to puerperal thromboembolism are combinations of relative late age and traumatic delivery, and there may well be others such as obesity and hypertensive states complicating pregnancy. It still remains uncertain how often it is these which prompt the administration of oestrogens to inhibit lactation.

At this stage of knowledge it may be concluded that, provided oestrogens have the inhibitory effect on breast activity which is credited to them, and which our observations lead us to accept as genuine, their administration does not increase the risk of puerperal thromboembolism to an unacceptable degree. This is true for women at low risk, but for those who are advanced in years and who are subjected to operative delivery involving considerable trauma there is some reason to hesitate to add one more predisposing factor, even if it be a minor one. Obesity and a past history of thromboembolic disorders might also sometimes be considered to be contraindications to the administration of oestrogens in the puerperium. When oestrogens are given, however, it would seem wise to use the lowest dose compatible with efficient inhibition of lactation.

A firm conclusion about the role of therapeutic doses of oestrogen in predisposing to puerperal thromboembolism may not be possible without controlled prospective studies, and these are already in progress. Because the incidence of clinicall evident disease is relatively low, this will take time. Meanwhile, the results of this retrospective study are reported to add to the evidence which needs to be collected from many sources.

\section{REFERENCES}

Arneil, G. C. (1967). Scottish Health Service Study, No. 6. Edinburgh. Burns, C. (1957). Med. Offr, 98, 205.

Daniel, D. G., Campbell, H., and Turnbull, A. C. (1967). Lancet, 2,

Daniel, D. G., Bloom, A. L., Giddings, J. C., Campbell, H., and Turnbull, A. C. (1968). Brit. med. F., 1, 801 .

Dykes, R. M. (1957). Lancet, 2, 230.

Garrey, M. M., Paterson, M. M., and Evans, J. M. (1964). Lancet, 2, 1057.

Hill, G. B., and Wilson, W. A. (1968). Med. Offr, 119, 147.

Hodge, C. (1967). Lancet, 2, 286.

Inman, W H. W., and Vessey, M. P. (1968). Brit. med. F., 2, 193.

Jeffcoate, T. N. A., Lister, Ursula M., Hargreaves, Betty, and Roberts, H. (1948). Brit med. F., 2, 809.

Jeffcoate, T. N. A., and Tindall, V. R. (1965). Aust. N.Z. F. Obstet. Gynaec., 5, 119.

Ministry of Health (1957, 1960, 1963, 1966). Reports on Confidential Enquirtes into Maternal Deaths, England and Wales. H.M.S.O., London.

Ministry of Health (1957a). Annual Report of the Chief Medical Officer. H.M.S.O., London.

Simpson Memorial Pavilion (1965). Annual Medical and Clinical Report. H.M.S.O., London.

Vessey, M. P., and Doll, R. (1968). Brit. med. F., 2, 199.

\title{
Circadian Variation of Glucose, Insulin, and Free Fatty Acids During Long-term Use of Oral Hypoglycaemic Agents in Diabetes Mellitus
}

\author{
A. N. RIGAS,* M.D. ; A. H. BITTLES, † F.I.M.L.T. ; D. R. HADDEN, $\ddagger$ M.D., M.R.C.P.ED. \\ D. A. D. MONTGOMERY,§ M.D., F.R.C.P.
}

Brit. med. F., 1968, 4, 25-28

\begin{abstract}
Cummary: The circadian rhythms of preprandial and $\$$ postprandial blood glucose, free fatty acids, and insulin levels were measured in groups of normal and of diabetic patients controlled by diet alone or by diet with tolbutamide, chlorpropamide, or metformin. All groups showed a greater insulin release after the first meal of the day than after subsequent meals. Diabetic patients controlled for more than two years on diguanide therapy showed the closest resemblance to non-diabetic control subjects. There was no significant difference between the values for diabetic patients on long-term control with diet alone and those on short- or long-acting sulphonylurea. The circadian rhythms disappeared in obese subjects on total starvation.
\end{abstract}

\section{Introduction}

The aim of therapy of maturity onset diabetes with oral hypoglycaemic agents is to achieve good long-term diabetic "control" in patients who do not respond to dietary measures alone. Good control of blood glucose levels has been said to

\footnotetext{
* Research Fellow.

+ Research Technician

¥ Physician, Metaholic Unit.

Physician-in-Charge, Metabolic Unit.

Sir George E Clark Metabolic Unit, Royal Victoria Hospital, Belfast, Northern Ireland.
}

prevent the development of vascular complications (Marble, 1965). Most studies of the action of hypoglycaemic agents have been concerned with the acute effect of the drug; there is little knowledge of what happens to patients in whom apparently good control is achieved over a prolonged period. Furthermore, possible differences between the available therapeutic agents have received little attention.

The present study was undertaken to document the changes of blood glucose, insulin, and free fatty acids in the fasting state and two hours after meals during the day in patients on different regimens (a restricted carbohydrate diet alone, or with tolbutamide, chlorpropamide, or metformin in addition), and to compare them with those found in normal persons and in obese patients undergoing total starvation.

\section{Patients and Methods}

Six groups of patients were studied (Table I). One of the two control groups consisted of three non-diabetic non-obese patients admitted to hospital for various medical conditions (simple goitre, Hashimoto's thyroiditis, cerebral angiospasm) who had a normal standard oral glucose tolerance test; the other group consisted of six normoglycaemic obese subjects who were undergoing a period of therapeutic total starvation. There were four groups of diabetic patients on restricted carbohydrate diet, or a similar diet in addition to three different oral hypoglycaemic agents. We attempted to make these groups 